\title{
Succinylated Bacterial Cellulose Induce Carbonated Hydroxyapatite Deposition in a Solution Mimicking Body Fluid
}

\author{
Farah Nurlidar ${ }^{1, *}$ and Mime Kobayashi ${ }^{2}$ \\ ${ }^{1}$ Center for Application of Isotopes and Radiation, National Nuclear Energy Agency, \\ Jl. Lebak Bulus Raya No. 49, Jakarta Selatan 12043, Indonesia \\ ${ }^{2}$ Graduate School of Materials Science, Nara Institute of Science and Technology, \\ 8916-5 Takayama, Ikoma, Nara 630-0192, Japan
}

* Corresponding author:

email:farah@batan.go.id

Received: April 25, 2018

Accepted: August 9, 2018

DOI: $10.22146 /$ ijc.35048

\begin{abstract}
Incorporation of bone-like hydroxyapatite into bacterial cellulose (BC) is an attractive approach for the fabrication of a bioactive three-dimensional (3D) scaffold for bone tissue regeneration. This study investigates the influence of the succinylation of $B C$ on its ability to incorporate bone-like hydroxyapatite. A biomimetic process using a $1.5 \times$ Simulated Body Fluid (SBF) was used to deposit the hydroxyapatite into the succinylated$B C$. After soaking the succinylated-BC in the $1.5 \times$ SBF for six days, Scanning Electron Microscope (SEM) images were taken and the composition of the succinylated-BC was analyzed by energy dispersive X-ray spectrometry. The biocompatibility of the scaffolds was tested in vitro using rat Bone Marrow Stromal Cells (rBMSCs). The SEM images and Fourier Transform Infrared Spectroscopy (FTIR) spectra showed that carbonated hydroxyapatite was deposited on the succinylated-BC. In contrast, only a small amount of carbonated hydroxyapatite deposition was observed on unmodified $B C$, indicating that the succinyl group in the BC is effective for inducing hydroxyapatite deposition. In vitro studies using rBMSCs revealed the biocompatibility of the scaffold. Combining with the ability of the cells to differentiate into bone cells, the succinylated-BC scaffold is a promising $3 D$ scaffold for bone tissue regeneration.
\end{abstract}

Keywords: bacterial cellulose; carbonated hydroxyapatite; $1.5 \times$ simulated body fluid; succinylation; $3 D$ scaffolds

\section{- INTRODUCTION}

Bone damage is usually repaired using implants, such as allografts or xenografts [1-5]. However, the amount of those grafts available for transplantation may be limited by donor shortage and a possibility of disease transfer $[1,3,5]$. To overcome these problems, polymeric three-dimensional (3D) scaffolds have gained interest in the reconstruction of damaged bone because of their abundant availability and ease of modification of their chemical and physical properties [3,5].

Bacterial cellulose (BC) has shown promise as a 3D scaffold for bone regeneration because of its high mechanical properties and excellent biocompatibility [611]. It has been reported that microporous $B C$ supports MC3T3-E1 osteoprogenitor cells to form cell clusters and deposit mineral on the $\mathrm{BC}$, indicating the potential of $\mathrm{BC}$ as a $3 \mathrm{D}$ scaffold for bone tissue regeneration [6]. However, BC shows poor bioactivity, rendering it difficult to make bonding with living bone. To design bioactive 3D scaffolds that have a high biological affinity to living bone, it is important to incorporate bone-like hydroxyapatite onto the 3D scaffold [2,4-5]. Bone-like hydroxyapatite can be incorporated into $3 \mathrm{D}$ scaffolds by the biomimetic process using a Simulated Body Fluid (SBF) solution that has similar $\mathrm{pH}$ and ion concentration with human blood plasma [2,4-5,12]. Some studies have reported the incorporation of bonelike hydroxyapatite onto $\mathrm{BC}$ by a biomimetic process [13-14]. However, there is little hydroxyapatite found on the unmodified BC surface after the biomimetic process, 
because its hydroxy group is not reactive enough to induce hydroxyapatite deposition [13-14]. Therefore, modification of $\mathrm{BC}$ with a functional group that can accelerate hydroxyapatite deposition may be necessary to achieve its bioactivity.

Previous studies reported that $3 \mathrm{D}$ scaffolds that contain functional groups such as carboxy and silanol groups could accelerate the deposition of calcium hydroxyapatite into scaffolds [15-16]. In this study, we modified BC with the succinyl group through a simple reaction with succinic anhydride. Succinylation may enhance the bioactivity of $\mathrm{BC}$ to deposit bone-like hydroxyapatite. The influence of succinylation of $\mathrm{BC}$ on its ability to incorporate bone-like apatite was then investigated.

\section{- EXPERIMENTAL SECTION}

\section{Materials}

Ammonium sulfate, sucrose, glacial acetic acid and $\mathrm{N}, \mathrm{N}$-dimethylformamide were purchased from Merck GmbH, Germany. N,N-Diisopropylethylamine (DIPEA) was purchased from Applied Biosystems (Carlsbad, CA, USA). Succinic anhydride was purchased from Wako Pure Chemical Industries Ltd. (Osaka, Japan) and recrystallized from 2-propanol prior to use. Other reagents were purchased from Wako Pure Chemical Industries Ltd.

\section{Procedure}

\section{Preparation of bacterial cellulose (BC)}

$B C$ was prepared using coconut water as a fermentation medium [9-10]. Briefly, the coconut water medium containing $5 \%(\mathrm{w} / \mathrm{v})$ sucrose and $0.5 \%(\mathrm{w} / \mathrm{v})$ ammonium sulfate was boiled, and the $\mathrm{pH}$ of the medium was adjusted to $\mathrm{pH} 4$ using glacial acetic acid. The medium was equilibrated to room temperature before use. Ten percent of pre-culture medium containing Acetobacter xylinum was then added into the medium. The mixture was incubated at room temperature for $2-3$ days. The obtained bacterial cellulose was washed with demineralized water and immersed in $0.1 \mathrm{M}$ sodium hydroxide at $60^{\circ} \mathrm{C}$ for $4 \mathrm{~h}$ to remove any residual bacteria. Finally, the pellicle was rinsed with demineralized water at

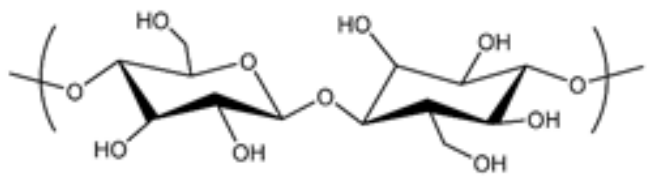

Bacterial Cellulose

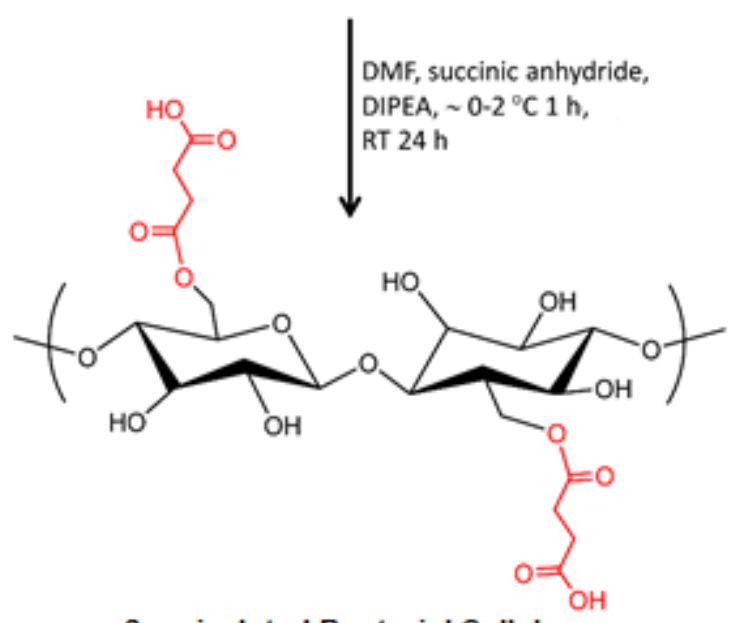

Succinylated Bacterial Cellulose

Fig 1. Reaction scheme of bacterial cellulose succinylation

room temperature to achieve a neutral $\mathrm{pH}$ and freezedried to obtain dried BC.

\section{Succinylation of $B C$}

Succinylated-BC was synthesized by reacting the $\mathrm{BC}$ with a 10-fold molar excess of succinic anhydride and DIPEA relative to the hydroxy groups of the $\mathrm{BC}$ in DMF on ice for $2 \mathrm{~h}$ and then for $24 \mathrm{~h}$ at room temperature (Fig. 1).

The succinylated-BC was then washed with demineralized water extensively to remove the DMF and unreacted substances, and freeze-dried. Succinylation of the BC was confirmed using a Spectrum One FTIR spectrometer (PerkinElmer, Wellesley, MA, USA) in the range of $400-4000 \mathrm{~cm}^{-1}$ based on the $\mathrm{KBr}$ method with 16 scans and a resolution of $1 \mathrm{~cm}^{-1}$.

\section{Biomimetic soaking of $B C$ and succinylated-BC}

To induce bone-like apatite deposition onto the $\mathrm{BC}$, we soaked the $\mathrm{BC}$ and succinylated-BC in $1.5 \times \mathrm{SBF}$ solution. The SBF solution was prepared as described previously [16]. BC and succinylated-BC were soaked in $0.2 \mathrm{M} \mathrm{CaCl}_{2}$ for $24 \mathrm{~h}$ and followed by soaking in $1.5 \times$ $\mathrm{SBF}$ solution for six days at $37^{\circ} \mathrm{C}$. The SBF solution was changed with fresh $1.5 \times \mathrm{SBF}$ solution every two or three 
days. After six days soaking, the $\mathrm{BC}$ and succinylated-BC were washed with demineralized water three times and dried at room temperature.

The BC and succinylated-BC were coated with gold and their microstructure and biological hydroxyapatite formation were analyzed using a scanning electron microscope (SEM; Model S-4800, Hitachi, Tokyo, Japan), and their composition using an energy dispersive X-ray spectrophotometer (EDX; Octane T Ultra W, EDAX Inc.). Furthermore, its functional groups were analyzed using a Spectrum One FTIR spectrometer (PerkinElmer) in the range of $400-4000 \mathrm{~cm}^{-1}$ based on the $\mathrm{KBr}$ method with 16 scans and a resolution of $1 \mathrm{~cm}^{-1}$.

\section{Biocompatibility of $B C$ and succinylated- $B C$}

Rat bone marrow stromal cells (rBMSCs) were obtained as described previously [17]. The rBMSCs were suspended in $\alpha$-minimum essential medium ( $\alpha$-MEM; Gibco Invitrogen Corp. Grand Island, NY, USA) containing 20\% fetal calf serum (FCS; HyClone, Logan, UT, USA) and cultured in an $80 \mathrm{~cm}^{2}$ tissue culture flask (153732; Nalge Nunc International) at $37{ }^{\circ} \mathrm{C}$ under $5 \%$ $\mathrm{CO}_{2}$ atmosphere. After three days, the attached cells were washed with PBS, treated with $0.02 \%$ ethylenediaminetetraacetic acid and $0.25 \%$ trypsin, and centrifuged at $1200 \mathrm{rpm}$ for $5 \mathrm{~min}$. After centrifugation, the cells were then re-suspended in $20 \% \mathrm{FCS} / \alpha-\mathrm{MEM}$ at a density of $5 \times 10^{6}$ cells $/ \mathrm{mL}$.

The rBMSC suspension was seeded on the BC scaffolds in a 24-well plate (142475; Nalge Nunc International) at a density of $5 \times 10^{4}$ cells/scaffold and incubated at $37{ }^{\circ} \mathrm{C}$ under $5 \% \mathrm{CO}_{2}$. The same number of rBMSCs without any samples was cultured in another well of the 24-well plate as a control. Every two or three days, half of the medium was replaced with fresh medium.

Cell viability was tested using a Cell Counting Kit-8 (Dojindo, Kumamoto, Japan) according to the manufacturer instruction. Optical density (OD) at $450 \mathrm{~nm}$ of samples, control, and the medium was then measured using a SpectraFluor Plus microplate reader (Tecan, Männedorf, Switzerland).

Cell viability $(\%)=\frac{\left(\mathrm{OD}_{450} \text { Sample }-\mathrm{OD}_{450} \text { Medium }\right)}{\mathrm{OD}_{450} \text { Control }-\mathrm{OD}_{450} \text { Medium }} \times 100 \%$

\section{Statistical analysis}

All statistical evaluations were performed using the one-way analysis of variance routine of KaleidaGraph 4.5 (Synergy Software, Reading, PA, USA) followed by Tukey's honest significant difference test. A value of $\mathrm{p}<$ 0.05 was accepted as statistically significant. All data were presented as mean \pm standard deviation, with $\mathrm{n}=3$.

\section{- RESULTS AND DISCUSSION}

\section{Synthesis and Characterization of Bacterial Cellulose (BC) and Succinylated-BC}

In this study, BC was reacted with succinic anhydride in the presence of DIPEA as a base catalyst. The catalyst facilitates the deprotonation of BC hydroxy groups and enables them to react with succinic anhydride to form succinylated-BC. Fig. 2 shows the FTIR spectra of unmodified BC and succinylated-BC.

Peaks at 3432 and $2900 \mathrm{~cm}^{-1}$ in the spectra correspond to $\mathrm{O}-\mathrm{H}$ stretching and $\mathrm{C}-\mathrm{H}$ stretching of $\mathrm{CH}_{2}$ in the $\mathrm{BC}$ structure, respectively. A new peak at $1735 \mathrm{~cm}^{-1}$ observed in the FTIR spectrum of succinylated-BC was assigned to the carbonyl $(-\mathrm{C}=\mathrm{O})$ ester stretching of the succinyl group. These results suggest that the succinyl groups were successfully conjugated to the BC. No peak that could be attributed to unreacted succinic anhydride was detected in the FTIR spectrum of succinylated-BC, indicating the high purity of the obtained succinylated-BC.

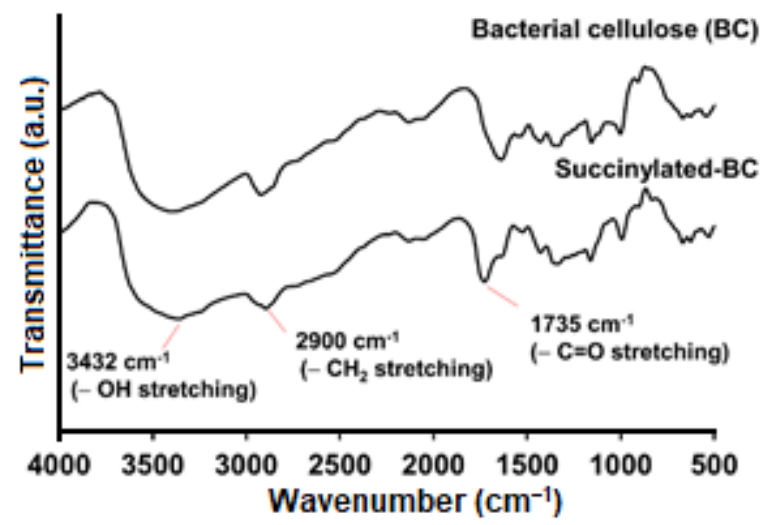

Fig 2. FTIR spectra of bacterial cellulose (BC) and succinylated-BC. FTIR measurement was conducted using the $\mathrm{KBr}$ method with $1 \mathrm{~cm}^{-1}$ resolution and 16 scans at room temperature 

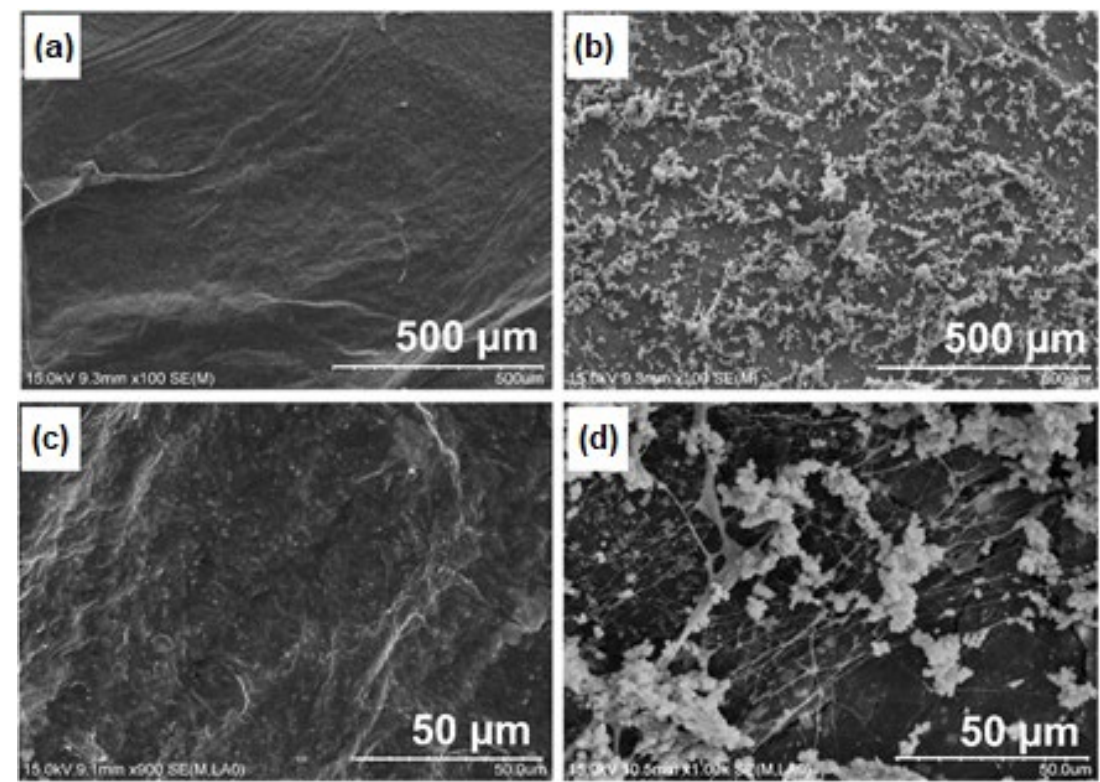

Fig 3. SEM images of bacterial cellulose ( $a$ and $c$ ) and succinylated bacterial cellulose ( $b$ and $d$ ) after 6 days immersion in $1.5 \times \mathrm{SBF}$ solution

\section{Bioactivity of BC and Succinylated-BC}

Bioactivity such as the capability to form direct bonds with natural bones is an important property for 3D scaffolds as bone repairing materials. In this study, an ability to form bone-like hydroxyapatite on surfaces was evaluated by soaking $\mathrm{BC}$ and succinylated-BC in $1.5 \times \mathrm{SBF}$ for 6 days. Before the soaking treatment, the $\mathrm{BC}$ and succinylated-BC were soaked in $0.2 \mathrm{M} \mathrm{CaCl}_{2}$ solution for $24 \mathrm{~h}$. Increasing the $\mathrm{Ca}^{2+}$ content in the scaffolds is effective to induce heterogeneous and homogeneous hydroxyapatite nucleation [16].

SEM images of $B C$ and succinylated-BC after six days of soaking in $1.5 \times \mathrm{SBF}$ are shown in Fig. 3. The SEM Images show the appearance of particle deposition on the surface of succinylated-BC (Fig. 3(b) and (d)). The morphology of the particles is similar to that of bone-like apatite [16]. Further analysis by EDX confirmed the presence of calcium and phosphorus in the particles, indicating the formation of hydroxyapatite on the $\mathrm{BC}$ and succinylated-BC surfaces (Fig. 4(a) and (b)). High intensities of calcium and phosphorus peaks are found on the EDX spectrum of succinylated-BC. In contrast, only small intensities of calcium and phosphorus peaks are observed in the EDX spectrum of unmodified BC. These results indicate that succinyl groups in succinylated-BC could accelerate hydroxyapatite formation on the $\mathrm{BC}$ surface.

The ability of the succinylated-BC to induce hydroxyapatite deposition may be caused by its succinyl group. The carboxy moiety $(-\mathrm{COOH})$ of the succinyl groups in the succinylated-BC are negatively charged at physiological environment $(\mathrm{pH}=7.4)$, allowing it to make an ionic interaction with calcium ion $\left(\mathrm{Ca}^{2+}\right)$ in solution to form $-\mathrm{COOCa}^{+}$and $(-\mathrm{COO})_{2} \mathrm{Ca}$ complexes that induce hydroxyapatite nucleation [16].

It has been reported that polyamide films containing carboxy groups can deposit bone-like hydroxyapatite on their surfaces after soaking in $1.5 \times$ SBF solution when they contain calcium chloride [16]. Hydroxyapatite deposition was induced by an increase of $\mathrm{Ca}^{2+}$ concentration on the surfaces of succinylated-BC which may increase the degree of supersaturation of the solution [16]. Further evidence of hydroxyapatite deposition on BC and succinylated-BC was confirmed by FTIR analysis. FTIR spectra of $\mathrm{BC}$ and succinylated$\mathrm{BC}$ after soaking in $1.5 \times \mathrm{SBF}$ solution for six days were shown in Fig. 5.

Peaks at 564 and $605 \mathrm{~cm}^{-1}$ in the FTIR spectrum of succinylated-BC were ascribed to $\mathrm{PO}_{4}{ }^{3-}$ bending vibration (O-P-O bond) [18-19]. Peaks at 1035 and $1058 \mathrm{~cm}^{-1}$ were 

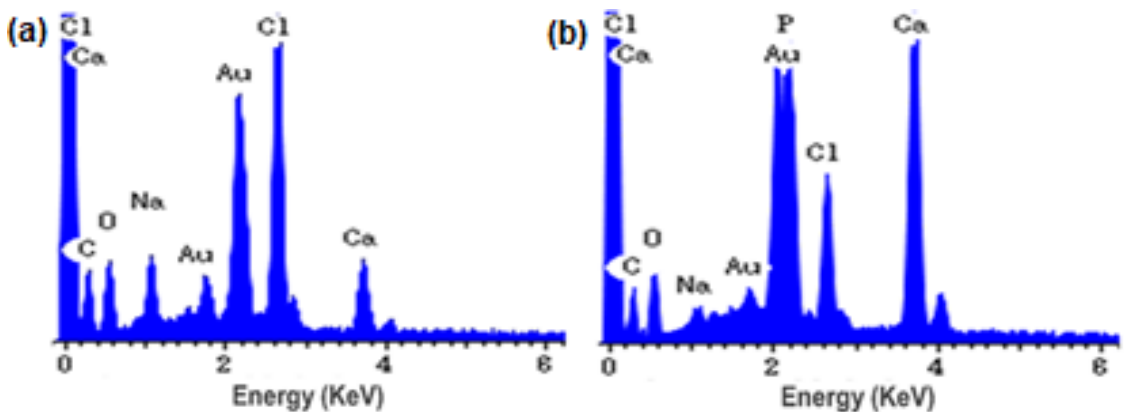

Fig 4. EDX spectra of bacterial cellulose (a) and succinylated bacterial cellulose (b) after 6 -day immersion in $1.5 \times \mathrm{SBF}$ solution

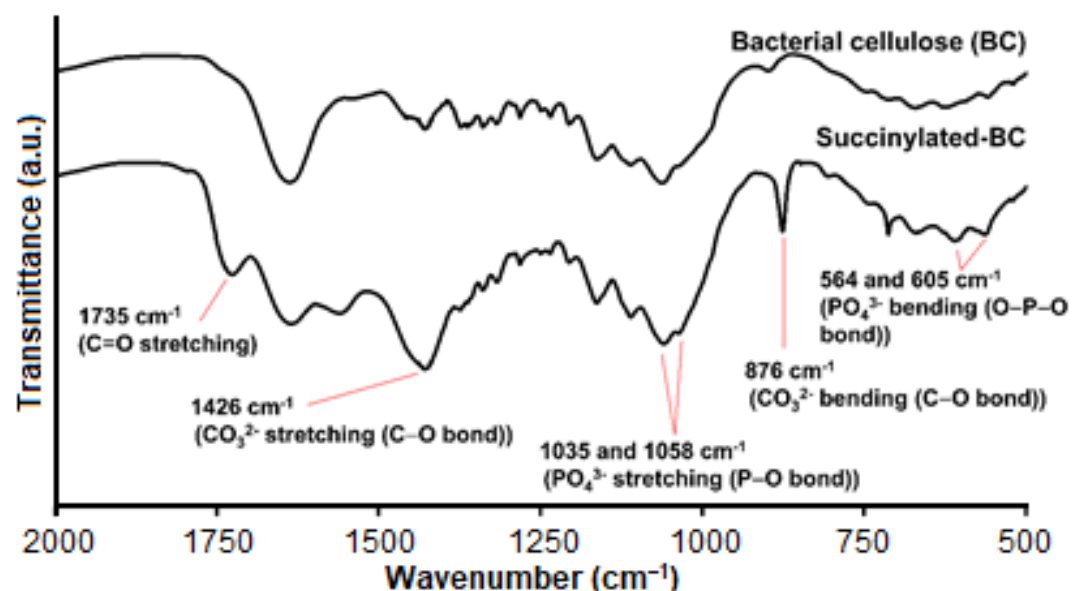

Fig 5. FTIR spectra of bacterial cellulose $(B C)$ and succinylated-BC after 6-day immersion in $1.5 \times$ SBF solution

assigned to $\mathrm{PO}_{4}{ }^{3-}$ stretching vibration ( $\mathrm{P}-\mathrm{O}$ bond). These results show the presence of phosphate groups in the deposited particles. In addition, peaks correlated with carbonate groups were also observed. Strong peaks at 876 and $1425 \mathrm{~cm}^{-1}$ are ascribed as $\mathrm{CO}_{3}{ }^{2-}$ bending and stretching vibration ( $\mathrm{C}-\mathrm{O}$ bond), respectively. These peaks are known to be specific for carbonated hydroxyapatite [18].

The results described above show that the deposited particles are carbonated hydroxyapatite. The carbonated hydroxyapatite has low crystallinity, quite similar to those of hydroxyapatite in living bone $[16,18]$. The formation of the carbonated hydroxyapatite on the succinylated-BC after soaking in $1.5 \times \mathrm{SBF}$ solution may enhance the ability of the scaffold to make a direct and strong bonding between the 3D scaffold and living bone [1,5]. The FTIR spectrum of BC shows only low intensities of carbonate peaks, indicating that the surface of unmodified $\mathrm{BC}$ is only slightly active towards hydroxyapatite deposition.
These results demonstrated that the succinyl group in the succinylated-BC plays an important role in activating the surface of $\mathrm{BC}$ to deposit hydroxyapatite. These results also suggest the potential of succinylated$\mathrm{BC}$ as a $3 \mathrm{D}$ scaffold for bone tissue regeneration.

\section{Biocompatibility}

Biocompatibility is an important characteristic of 3D scaffolds intended for biomedical applications. Furthermore, the 3D scaffolds must have good biocompatibility with surrounding cells to promote cell proliferation and differentiation [3]. The biocompatibility of the scaffolds was tested in vitro using rBMSCs. The WST-8 assay results demonstrated that cells in the BC and succinylated-BC were alive and proliferated, indicating the biocompatibility of $\mathrm{BC}$ and succinylatedBC (Fig. 6). These results suggest that incorporation of negatively charged groups into BC does not influence cell viability, further indicating the biocompatibility of 


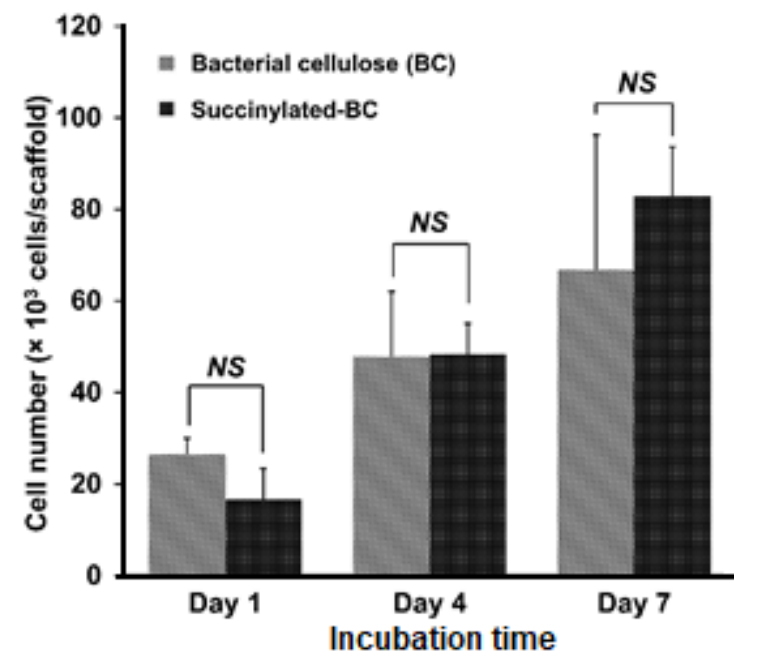

Fig 6. The viability of rat bone marrow stromal cells after seeded on bacterial cellulose (BC) and succinylated-BC and incubated for 7 days. NS = not significant

the succinylated-BC. It has been reported that succinylation of a collagen-like polypeptide similarly did not influence the biocompatibility of the polypeptide for rBMSCs [20-21]. Considering its biocompatibility, bioactivity and the ability of the cells to differentiate into bone cells, the succinylated-BC has potential as a 3D scaffold for reconstructing damaged bone.

\section{- CONCLUSION}

Bacterial cellulose (BC) was successfully modified through simple reaction with succinic anhydride and DIPEA. Succinylation of BC was effective in accelerating bone-like apatite formation on the $\mathrm{BC}$ surface after soaking in $0.2 \mathrm{M} \mathrm{CaCl}_{2}$ solution for 1 day and $1.5 \times \mathrm{SBF}$ solution for 6 days. These results indicate that modification of an inert 3D scaffold with functional groups containing carboxy groups, such as succinyl group, is effective in inducing bone-like apatite deposition.

\section{- ACKNOWLEDGMENTS}

This study was partly supported by The Global Collaboration Project (NAIST-Indonesia) in NAIST supported by the MEXT, Japan. English proofreading by Leigh McDowell is also acknowledged.

\section{- REFERENCES}

[1] Janicki, P., and Schmidmaier, G., 2011, What should be the characteristics of the ideal bone graft substitute? Combining scaffolds with growth factor and/or stem cells, Injury, 42 (Suppl. 2), 77-581.

[2] Swetha, M., Sahithi, K., Moorthi, A., Srinivasan, N., Ramasamy, K., and Selvamurugan, N., 2010, Biocomposites containing natural polymers and hydroxyapatite for bone tissue engineering, Int. J. Biol. Macromol., 47 (1), 1-4.

[3] O'Brien, F.J., 2011, Biomaterials and scaffolds for tissue engineering, Mater. Today, 14 (3), 88-95.

[4] Kepa, K., Coleman, R., and Grøndahl, L., 2015, In vitro mineralization of functional polymers, Biosurf. Biotribol., 1 (3), 214-227.

[5] Raucci, M.G., Guarino, V., and Ambrosio, L., 2012, Biomimetic strategies for bone repair and regeneration, J. Funct. Biomater., 3 (3), 688-705.

[6] Zaborowska, M., Bodin, A., Bäckdahl, H., Popp, J., Goldstein, A., and Gatenholm, P., 2010, Microporous bacterial cellulose as a potential scaffold for bone regeneration, Acta Biomater., 6 (7), 2540-2547.

[7] Ullah, H., Wahid, F., Santos, H.A., and Khan, T., 2016, Advances in biomedical and pharmaceutical applications of functional bacterial cellulose-based nanocomposites, Carbohydr. Polym., 150, 330-352.

[8] Shah, N., Ul-Islam, M., Khattak, W.A., and Park, J.K., 2013, Overview of bacterial cellulose composites: A multipurpose advanced material, Carbohydr. Polym., 98 (2), 1585-1598.

[9] Darwis, D., Khusniya, T., Hardiningsih, L, Nurlidar, F., and Winarno, H., 2012, In-vitro degradation behaviour of irradiated bacterial cellulose membrane, Atom Indonesia, 38 (2), 78-82.

[10] Darwis, D., Hardiningsih, L., Nurlidar, F., and Fajarsyah, R., 2012, Biological Evaluation of Irradiated Bacterial Cellulose (BC) Membrane for Application in Guided Bone Regeneration, Proceedings of The International Conference on Innovation in Polymer Science and Technology 2011, 
Indonesian Polymer Association, Bali, 28 November - 1 December 2011, 205-210.

[11] Yang, M., Zhen, W., Chen, H., and Shan, Z., 2016, Biomimetic design of oxidized bacterial cellulosegelatin-hydroxyapatite nanocomposites, J. Bionic Eng., 13 (4), 631-640.

[12] Palmer, L.C., Newcomb, C.J., Kaltz, S.R., Spoerke, E.D., and Stupp, S.I., 2008, Biomimetic systems for hydroxy hydroxyapatite mineralization inspired by bone and enamel, Chem. Rev., 108 (11), 4754-4783.

[13] Ahn, S.J., Shin, Y.M., Kim, S.E., Jeong, S.I., Jeong, J.O., Park, J.S. Gwon, H.J., Seo, D.E., Nho, Y.C., Kang, S.S., Kim, C.Y., Huh, J.B., and Lim, Y.M., 2015, Characterization of hydroxyapatite-coated bacterial cellulose scaffold for bone tissue engineering, Biotechnol. Bioprocess Eng., 20 (5), 948-955.

[14] Wan, Y.Z., Huang, Y., Yuan, C.D., Raman, S., Zhu, Y., Jiang, H.J., He, F., and Gao, C., 2007, Biomimetic synthesis of hydroxyapatite/bacterial cellulose nanocomposites for biomedical applications, Mater. Sci. Eng., C, 27 (4), 855-864.

[15] Morita, Y., Matsumoto, C., Miyazaki, T., Ishida, E., Tanaka, K., and Goto, T., 2009, Apatite deposition on hyaluronic acid gels in biomimetic conditions, Trans. Mater. Res. Soc. Japan, 34 (1), 85-87.

[16] Kawai, T., Ohtsuki, C., Kamitakahara, M., Hosoya, K., Tanihara, M., Miyazaki, T., Sakaguchi, Y., and Konagaya, S., 2007, In vitro apatite formation on polyamide containing carboxyl groups modified with silanol groups, J. Mater. Sci. - Mater. Med., 18, 1037-1042.

[17] Saito, A., Suzuki, Y., Ogata, S., Ohtsuki, C., and Tanihara, M., 2005, Accelerated bone repair with the use of a synthetic BMP-2-derived peptide and bone marrow stromal cells, J. Biomed. Mater. Res. Part A, 72 (1), 77-82.

[18] Stoch, A., Jastrzębski, W., Brożek, A., Trybalska, B., Cichocińska, M., and Szarawara, E., 1999, FTIR monitoring of the growth of the carbonate containing hydroxyapatite layers from simulated and natural body fluids, J. Mol. Struct., 511-512, 287-294.

[19] Garskaite, E., Gross, K.A., Yang, S.W., Yang, T.C.K., Yang, J.C., and Kareiva, A., 2014, Effect of processing conditions on the crystallinity and structure of carbonated calcium hydroxyapatite (CHAp), CrystEngComm, 16 (19), 3950-3959.

[20] Nurlidar, F., Kobayashi, M., Terada, K., Ando, T., and Tanihara, M., 2017, Cytocompatible polyion complex gel of poly(Pro-Hyp-Gly) for simultaneous rat bone marrow stromal cell encapsulation, J. Biomater. Sci., Polym. Ed., 28 (14), 1480-1496.

[21] Kusumastuti, Y., Shibasaki, Y., Hirohara, S., Kobayashi, M., Terada, K., Ando, T., and Tanihara, M., 2017, Encapsulation of rat bone marrow stromal cells using a poly-ion complex gel of chitosan and succinylated poly(Pro-Hyp-Gly), $J$. Tissue Eng. Regener. Med., 11 (3), 869-876. 